Тютюнников А.А. Герман Коген: идея трансцендентального метода (часть I) // Вестник ПНИПУ. Культура. История. Философия. Право. - 2018. - № 2. - С. 7-26. DOI: 10.15593/perm.kipf/2018.2.01

Tyutyunnikov A.A. Hermann Cohen's transcendental method as a project (I). Bulletin of PNRPU. Culture. History. Philosophy. Law, 2018, no. 2, pp. 7-26. DOl: 10.15593/perm.kipf/2018.2.01

ФИЛОСОФСКИЕ НАУКИ

DOI 10.15593/perm.kipf/2018.2.01

УДК 111.8

ГЕРМАН КОГЕН: ИДЕЯ ТРАНСЦЕНДЕНТАЛЬНОГО МЕТОДА (ЧАСТЬ І) ${ }^{1}$

\author{
А.А. Тютюнников \\ Пермский государственный национальный \\ исследовательский университет, Пермь, Россия \\ ORCID https://orcid.org/0000-0003-2549-7773
}

\begin{abstract}
Представленная здесь в новом переводе глава «Трансцендентальный метод» из второго издания «Кантовской теории опыта» Г. Когена имела для самого основоположника Марбургской школы неокантианства программное значение. Начертанный Когеном проект философского метода сохраняет свою актуальность и для сегодняшней науки, нуждающейся на переднем крае своем в новой методологии. В статье «Введение в трансцендентальный метод», предваряющей перевод, первый эскиз этого метода, набросанный Когеном в работе «Кантовское обоснование этики», помещается в проясняющие его контексты. Рефлективная природа трансцендентального метода, понимаемого и как интеллигибельное основание объективной реальности, и как, в более узком смысле, учение об основаниях ее, обнаруживает классическую тему тождества субъекта и объекта. Это позволяет, с одной стороны, соотнести трансцен-

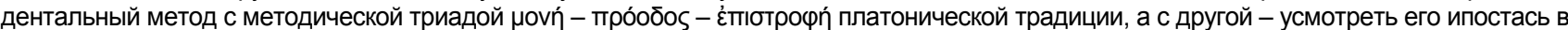
кантовском «чистом естествознании», предметом которого являются условия возможного опыта. Возможность такого двоякого соотнесения вытекает из того, что кантовская трансцендентальная идея может быть истолкована как платоновская идея. «Углубляя» таким образом Канта Платоном, Коген избавляет кантовскую видимость от миопии чувственности и тем самым обращает эту видимость в платоновское интеллектуальное ви́дение. Кроме того что интеллектуализация Когеном чувственности означает придание пространству и времени статуса категорий, которые затем расширяются до идей (основоположения при этом переходят в максимы, а явления в ноумены), она означает также распространение компетенции математики и чистого естествознания на весь возможный опыт, уже не ограниченный сферой чувственности. Благодаря соединению спекулятивных элементов с математикой и наблюдательной данностью трансцендентальный метод может проложить «верный путь науки» современной математической физике - даже там, где этот «возможный опыт» не может стать «действительным», реализованным в экспериментах и наблюдениях.

Ключевые слова: неокантианство, Герман Коген, Кант, трансцендентальный метод, априоризм, метафизика, физика, математика, эмпирический реализм.
\end{abstract}

\title{
HERMANN COHEN'S TRANSCENDENTAL METHOD AS A PROJECT (I)
}

\author{
Aleksandr A. Tyutyunnikov \\ Perm State National Research University, Perm, Russian Federation
}

ORCID https://orcid.org/0000-0003-2549-7773

The chapter on the transcendental method from the second edition of Hermann Cohen's Kant's Theory of Experience is presented here in a new Russian translation from German. For Cohen himself this chapter was of key importance. The project of a philosophical method that was conceived by the founder of the Marburg School of neo-Kantianism remains relevant up to the present time as far as the science of today, on its frontiers, needs a new methodology. The prolegomenous article "An Introduction to the Transcendental Method" contextualizes the first sketch of the method, drawn by Cohen in his Kant's Foundations of Ethics, for gaining more clarity. As the intelligible basis of objective reality and, in a narrower sense, as a theory concerning the foundations of that, the transcendental method has a reflexive nature betraying the classic theme of subject-object identity. This enables the transcendental method to be brought into correlation, on the one hand, with

(c) Тютюнников Александр Александрович - кандидат философских наук, доцент кафедры культурологии и социальногуманитарных технологий, e-mail: atutun@list.ru.

1 Вынесенный в приложение к настоящей публикации перевод был выполнен в рамках проекта, поддержанного РФФИ (проект 10-06-00557-a, 2010-2011 гг.). Автор выражает благодарность Ольге Ведерниковой и Свену Ауленбахеру за консультационную поддержку. 


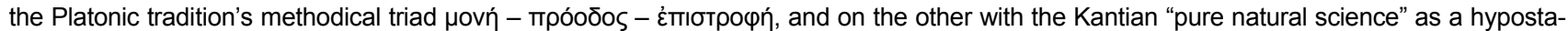
sis sui generis of the method, for both of them prove to be on and about law of experience. The possibility of such twofold correlation comes about through the circumstance that the Kantian transcendental idea can be eventually identified with Plato's idea. With "deepening" Kant through Plato in such a way, Cohen rids the Kantian "illusion" of the myopia of sensibility and thereby turns the illusion into Plato's intellectual intuition. As well as the intellectualization of sensibility imports the status of categories to space and time, expanding further all categories to ideas (principles ending in maxims, appearances - in noumena), it imports also the expansion of the competence of mathematics and pure natural science over all possible experience that is no longer limited by sensibility. By joining speculative elements with mathematics and the observably given, the transcendental method can shape the "secure course of a science" for modern mathematical physics, and can do it even where the possible experience is inaccessibly far from being actualized, experimentally and observably realized.

Keywords: neo-Kantianism, Hermann Cohen, Kant, the transcendental method, apriorism, metaphysics, physics, mathematics, empirical realism.

\section{Введение в трансцендентальный метод}

Второе издание «Кантовской теории опыта» (1885) - значительного труда главы Марбургской школы неокантианства Германа Когена - открывалось, в отличие от первого издания (1871), обширным введением, которое свидетельствовало о новом взгляде автора на кантовскую теоретическую философию. Эволюции когеновского прочтения Канта в немалой степени способствовала публикация в 1882-1884 годах Рудольфом Райке рукописей Канта, известных как «Opus postumum» [1]. Выдержки из этих рукописей Коген приводит и в своем Введении. Он, в частности, цитирует это место: «Наука о природе, которая должна проистекать из принципов a priori, без которых она не была бы научной, вращается вокруг двух петель или опирается на два крыла: одно - философии, другое - математики. Не так, что они присоединяются друг к другу в качестве двух специфически различных наук как дополнение одна другой, но мыслятся как связанные друг с другом в одну систему (из которой обе они происходят)... » [2, с. 473].

Коген не мог пройти мимо кантовской идеи трансцендентальной философии, в которой математика получила бы философское применение ${ }^{2}$. Эта идея, если и не была у него непосредственно источником понятия трансцендентального метода, то, по меньшей мере, сказалась в том аспекте метода, которым он обращен к исследованию природы. Ни где-либо у Канта, ни у Когена в первом издании «Кантовской теории опыта» сам термин «трансцендентальный метод» не встречается. Но во втором издании Коген посвящает этому методу заключительную главу Введения, которая, очевидно, имеет программное для него значение.

Если судить, однако, по первому эскизу трансцендентального метода в трактате Когена «Кантовское обоснование этики» (1877), «авторское право» на этот метод принадлежит Канту. Сам Кант рассматривал критику разума как план и фундамент будущей метафизики, метафизики природы и метафизики нравов, и уже этот план, полагает Коген, Кант чертит nach transzendentaler Methode, сообразно с трансцендентальным методом. Наверное, Кант мог бы явно сформулировать этот метод, тем более что он недвусмысленно заявлял о методическом значении критики чистого разума: «Эта критика есть трактат о методе, а не система самой науки, но тем не менее она заключает в себе полный очерк системы метафизики, как в отношении ее границ, так и в отношении всего внутреннего расчленения ее» [3, с. 38]. И если метод есть предмет кантовской критической философии, то прежде всего как предмет интелли-

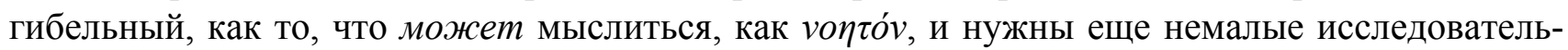
ские усилия к тому, чтобы ноэтическое в отношении к нашей способности умственного восприятия стало в нас образом ноуменальной формы самого предмета: чтобы трактуемое стало формулируемым. Все творчество Когена, по замечанию его сподвижника П. Наторпа, было направлено, в конце концов, к этой цели - выявить (herauszustellen) у Канта метод.

Вот и в «Кантовском обосновании этики» Коген понимает трансцендентальный метод как интеллигибельный предмет, зиждущий и определяющий объективную реальность [4, S. 11]. Та-

${ }^{2}$ Эта идея была намечена Кантом уже в «Критике чистого разума», но именно «Opus postumum» (главным образом рукописи первой папки) впервые ставит вопрос о математике как инструменте трансцендентальной философии. 
кое понимание делает понятным и то оговариваемое Кантом обстоятельство, почему трактат о методе намечает границы и структуру (Gliederbau) метафизики: так должно быть, если метафизика, со своей стороны, есть методология, если последний предмет метафизики, ноуменальная реальность, кантовское Ding an sich, есть метод.

В духе кантовской системы, в которой теоретическая философия завершается практической, трансцендентальный метод у Когена прежде всего направлен в сферу этики, где он исходя из идеи свободы «приводит к определению вида и степени реальности нравственного» [4, S. 132]. Эта реальность понимается Когеном не антропологически, но вполне объективно, так что наравне с тем, как мыслится само бытие, «нравственное должно было бы существовать, даже если бы не было людей» $[4$, S. 140]. Вообще говоря, объективность созидаемой методом реальности обеспечивается трансцендентальным a priori практического и теоретического применения разума. Это трансцендентальное a priori должно быть строго отличено от a priori метафизического. Послед-

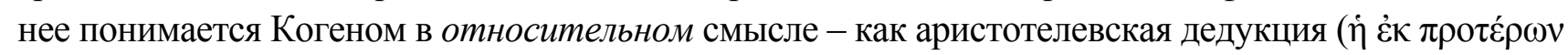

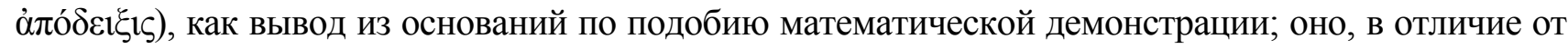
первого, не обязательно возводится к беспредпосылочному началу (das Unbedingte). Tакое a priori не только не изначально, но, быть может, и не вполне чисто, поскольку «чистота» его, то есть неэмпирический характер следствий, зависит от чистоты оснований, для установления которой самого метафизического a priori недостаточно. Коренной недостаток кантовского изложения теории опыта Коген усматривает в том, что это «совершенно новое» трансцендентальное a priori сплошь и рядом путается здесь со старым метафизическим a priori аристотелевского типа [4, S. 24].

Впрочем, это требуемое Когеном различение в кантовском a priori коррелирует с установленным самим Кантом различием между метафизическим и трансцендентальным рассмотрением пространства и времени, между метафизической и трансцендентальной, субъективной и объективной дедукцией категорий․․ В этическом контексте особое значение для Когена имеет кантовская дедукция категорий, необходимость и пользу которой для теологии и морали отмечает сам Кант в «Критике практического разума». Допускаемое Кантом в читателе первой своей «Критики» сомнение в основательности предпринятой им субъективной дедукции разделяется и читателем Когеном. Синтетическое единство сознания, исходный пункт этой дедукции, есть то понятие у Канта, в котором «в высшей степени недвусмысленно обнаруживается совмещение трансцендентального с метафизическим»; a priori выступает здесь, говорит Коген, «не столько как условие опыта, сколько в качестве основы нашей организации»; и так как основа всякой дедукции - единство сознания, создается видимость, будто в основе кантовской субъективной дедукции категорий лежит психологический факт [4, S. 46]. Предвидя неубедительность психологической мотивировки категорий, Кант сообщает читателю первого издания «Критики чистого разума», что придает наибольшее значение объективной их дедукции, определяющей не то, как возможен рассудок с присущими ему познавательными способностями, но то, «что и насколько может быть познано рассудком и разумом независимо от всякого опыта» [3, с. 27]. Именно на объективную дедукцию категорий Кант смещает акцент во втором издании этой «Критики», отказываясь от психологического определения категорий как оснований для рекогниции многообразного [3, с. 145-146].

\footnotetext{
${ }^{3}$ Необходимо отметить, однако, что у самого Канта различие между субъективной и объективной дедукцией не совпадает с различием между метафизической и трансцендентальной дедукцией [3, с. 166]. Можно ли говорить о какой-либо примеси субъективности в метафизической дедукции, если она возводит категории к совершенно объективным логическим функциям мышления, в соответствии с которыми понятия определенным образом связываются в суждении? Правда, Коген и в кантовской метафизической дедукции распознает психологический (субъективный) мотив, который дает себя знать в представлении об обязательности синтетического единства для всякого априорного суждения, о чем еще будет сказано ниже. Трудность проведения различия между «субъективным» и «объективным», конечно, заключается в том, что в свете трансцендентальной субъективности все объективное субъективно.
} 
Если же строго различить между метафизическим и трансцендентальным a priori, места сомнениям не остается: «априорность категорий заключена в основоположениях» [4, S. 57]. Возводить априорность категорий к синтетическому единству, обязательному для суждений, значит, по Когену, связываться с психологией. Но то, «что кажется психологически необходимым, не обусловливает оттого трансцендентально» [4, S. 57]. Для Когена категории - не что иное, как Kernpunkte der Grundsätze (ключевые моменты основоположений), и только в этом качестве они обладают своей априорной значимостью. Таким образом, в трансцендентальном смысле «вопрос об априорности категорий углубляется вопросом об априорности основоположений» $[4$, S. 58]. Что касается субъективной дедукции, то дело ее, конечно, не в том, чтобы показать необходимость категорий для последовательности актов души: восприятие - аппрегензия - ассоциация - репродукция - рекогниция. Настоящее дело ее, трансцендентально осмысленное, - в том, чтобы показать, «каким образом нормативный характер основоположений становится обязательным для человеческого мышления» [4, S. 57].

Итак, трансцендентальный метод есть дедуктивный метод, характер которого имеет значение нормы не просто для человеческого мышления, но - что делает Когена Когеном - для научного мышления, поскольку оно направлено на объективную реальность, укорененную в неизменных законах опыта. «Внутри сферы этого метода, - пишет Коген, - не существует никакого другого способа объективации, нежели при помощи дедукции из условий опыта» [4, S. 23]. В другом месте, открывая в этической перспективе свое учение об опыте, он называет трансцендентальный метод учением об условиях опьта [4, S. 18]. В связи с этим нельзя не заметить, что трансцендентальный метод понимается им двояко. Во-первых, как то, на чем непосредственно основана объективная реальность: јеne transzendentale Methode nichts Geringeres verkündete, als objektive Realität zum ersten Male begründet zu haben $[4, \mathrm{~S} .11]^{4}$. Во-вторых, в более узком смысле (и этот смысловой оттенок, возможно, тоже присутствует в приведенной здесь фразе) как учение об основаниях объективной реальности. В таком двояком понимании, очевидно, присутствует классическая тема тождества субъекта и объекта. Трансцендентальный метод есть самообъективирующееся беспредпосылочное начало («чистая воля» у Когена), точнее говоря, способ самообъективации этого начала. Трансцендентальная дедукция имеет у Когена то же методическое значение, что и

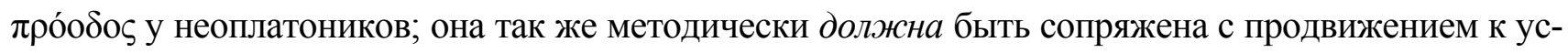

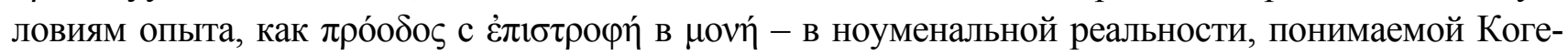
ном как вечно пребывающая задача (Aufgabe) научного поиска. Поэтому «тот» трансцендентальный метод привходящим образом оказывается «этим»: научным познанием, устремленным к основаниям объективной реальности, а в философской составляющей познания - критическим мышлением, гарантирующим правильность этих его устремлений проверкой априорной значимости его элементов, проверкой его «чистоты».

Поэтому выражения «трансцендентальный метод», «философский метод» и «критический метод» часто выступают у Когена как синонимы. В своей критической функции трансцендентальный метод не подменяет собой методы научного познания: чтобы, судя по всему, не войти в противоречие с «той», последней своей инстанцией. Не стремится он отыскать и «последние формальные элементы нашего мышления», нам вообще недоступные: в частно-

4 Точная цитата: «Wie jene transzendentale Methode nichts Geringeres leistete, als objektive Realität festzustellen, und nichts Geringeres verkündete, als dieselbe zum ersten Male begründet zu haben: so könnte ja auch eine reine Ethik die Realität jenes Sittlichen in einer tieferen Weise begründen, als die Abstraktion des erfahrungsmäßig Sittlichen dies zu gewährleisten vermag» (Так же, как поистине не малым делом «того» трансцендентального метода было определение объективной реальности, и как открыл он [нам] ни много, ни мало как то, что она непосредственно зиждется в нем, так, разумеется, и реальность «той» морали могла бы быть более глубоко и более надежно обоснована чистой этикой, нежели на то способна абстракция «этой», эмпирически обусловленной, нравственности). Это «јепе» здесь

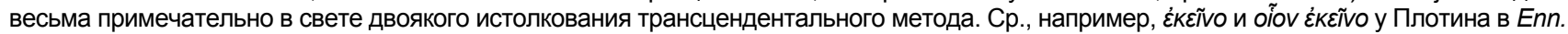
V. 4, 2, 22-26 (здесь, как и везде в основном тексте, если это не оговорено в ссылке, перевод автора.). 
сти, полагает Коген, он удерживает нас от попыток ответить на вопрос, почему мы обладаем пространственным созерцанием и отчего мы мыслим в определенных категориях [4, S. 236]. Но основоположения, «сердцевину» которых составляют чистые созерцания и категории ${ }^{5}$, могут и должны быть предметом критического дискурса: «Трансцендентальный метод не ищет те привходящие (etwaigen) последние формальные элементы нашего мышления, но зато отыскивает высшие основоположения действительного опыта, овеществленного в печатных книгах (in gedruckten Büchern wirklich gewordenen). А если уж требуется, чтобы эти основоположения имели априорную значимость в границах предполагаемого опыта, то их нельзя выводить из мира вещей - так как a priori есть то, “что мы сами вкладываем в вещи”, - и здесь выступает следующий метафизический аргумент: основоположения берут свои “истоки” в формах нашего мышления, в функциях суждения; условия опыта оказываются, таким образом, формальными условиями его» [4, S. 27].

Устанавливая в этом критическом дискурсе априорную значимость элементов научного познания, трансцендентальный метод обосновывает опыт в его возможности. Хотя он и принимает во внимание наличный, действительный опыт, дело его - как именно критического метода - не в том, чтобы вывести наличный опыт из понятия возможного опыта. Дело его, как и всей трансцендентальной философии, в том, чтобы найти условия, «которые делают наличный опыт возможным, и притом делают его возможным таким способом, что он может быть рассмотрен как имеющий силу a priori, то есть так, что ему могут быть усвоены строгая необходимость и неограниченная всеобщность» [4, S. 24]. Такими свойствами обладает опыт, который мы находим в математике и так называемом «чистом» естествознании - концептуальном ядре ньютоновской математической «натуральной философии». Дело, стало быть, в том, чтобы обосновать сам факт математики и математического естествознания.

Прецедентом на этом пути трансцендентальной философии служат Когену «Пролегомены» Канта. Но, как и всегда, Коген стремится улучшить применение метода. Признавая для себя возможным самостоятельно строить на заложенном Кантом фундаменте и по намеченному им плану, «свободно и по одному отбирая каждый камень, не ограничивая себя в проверке пригодности каждого из них, с бесспорным правом вкладывая, если придется, недостающие понятия и устраняя ложные» [4, S. 215], Коген «платонизирует» Канта - благо сам Кант дал непосредственный повод к этому, сравнив свои трансцендентальные идеи с платоновскими идеями. Призыв «Назад к Канту!» звучит для Когена и как призыв «Назад к Платону!».

Уже в следующем году после выхода «Кантовского обоснования этики» Коген представит работу «Платоновское учение об идеях и математика» (1878) [5].

Хорошо известна главная мысль этого эссе: идея есть гипотеза, определяющая цель и ценность научного познания. Своими корнями мысль эта уходит как в платоновскую философию, так и в философию Канта. Но платоновская $\theta \varepsilon \omega \rho i ́ \alpha$ для Когена все же глубже кантовской, так что его версия платонизма есть онтологическая подоснова кантовской эпистемологии.

По убеждению Когена, платоновское учение об идеях впервые в истории человеческой мысли ставит проблему познания. Саму эту проблему он характеризует здесь в духе Канта как проблему возможности знания. Более полно он определяет ее как «критический мотив» учения об идеях, как работающий в самой платоновской идее и постоянно ее порождающий вопрос о возможности знания, об основаниях и критериях достоверности познания, о видах и степенях этой достоверности. Математика помещается Когеном в самое средоточие этой про-

${ }^{5}$ В качестве ключевых моментов основоположений «чистые созерцания» - пространство и время - трактуются, в конце концов, Когеном как категории в суждениях цельности (Allheit) и множественности (Mehrheit). В этом - квинтэссенция когеновской программы интеллектуализации чувственности. 
блемы, поскольку у самого Платона она занимает промежуточное положение между идеями и чувственно воспринимаемыми предметами. Коген хочет пролить свет на смысл и ценность идей, выявляя «действенное значение» (Geltungswert) математических предметов, поскольку они стоят в определенном отношении к идеям. В связи с этим Когена занимает, во-первых, вопрос об онтологическом статусе предметов математики, как она понималась Платоном; вовторых, вопрос о ее методе. Чистое математическое мышление уравнивается Когеном с «мышлением идей», прежде всего, в том открытом Платоном интеллектуальном созерцании, или «ви́дении» (Schau), в котором предмет ви́дения совпадает с самим этим ви́дением, а затем в некотором вневременно́м смысле - в методе. Ибо метод заключает в себе это фундаментальное свойство «ви́дения»: если дан метод, то тем самым заданы и конструируемые этим мето-

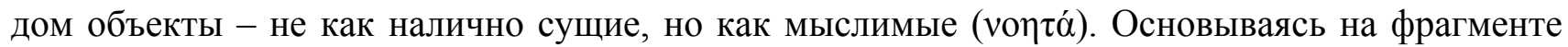
510 b 4-9 шестой книги «Государства», в котором речь идет о двух верхних отрезках «линии Платона», лежащих над областью чувственно воспринимаемого, Коген характеризует диалектический метод мышления идей и метод математического мышления в их общей родовой основе как метод гипотезы. Различие между этими методами - в различии целей того и другого (один устремлен к «началу» - другой к «завершению»), а также в различии средств, используемых тем и другим (первый действует без образов, посредством одних идей - второй использует образы). В силу методического родства с диалектикой математика обеспечивает, по словам Когена, «теоретико-познавательную легитимность, возникшую из платоновской характеристики геометрического мышления», того положения, что «сама идея мыслится как zипотеза» [5, S. 26]. Отстаиваемое Кантом право разума на гипотетическое применение находит в платоновской идее свое основание. Кантовский критический идеализм становится у Когена математическим реализмом, предвосхищающим «тенденцию трансцендентального метода к определению объективной реальности». В когеновской версии платоновского идеализма сама эта тенденция получает реалистическое истолкование.

Что же здесь, в «Кантовском обосновании этики»? Интегральный результат улучшенного, на когеновский манер, применения метода, сближающий Канта с Платоном, можно выразить в двух словах: интеллектуализация чувственности. Платоновский интеллигибельный мир настолько превосходит мир чувственный, что даже в дальней перспективе нет того, чтобы он уступал последнему в реальности: der mundus intelligibilis, weit gefehlt, daß er an Realität dem mundus sensibilis nachstände, übertrifft den letztern [4, S. 141]. Кант, как мы знаем, ставит в заслугу Платону открытие им этого интеллигибельного мира. Но - мы это также знаем - он разделяет и аристотелевскую критику Платона, идеализм которого Кант называет «мечтательным» [6, с. 193сн.]. «У Платона, - пишет Кант, сравнивая его с Аристотелем, - идеи суть первообразы самих вещей, а не только ключ к возможному опыту, каковы категории» [3, с. 296]. В духе аристотелевской критики и по-кантовски язвительно-метафорически звучит и этот пассаж: «Рассекая в свободном полете воздух и чувствуя противодействие его, легкий голубь мог бы вообразить, что в безвоздушном пространстве ему было бы еще легче летать. Так, Платон покинул [область] чувственного мира, потому что он ставит узкие границы рассудку, и отважился пуститься за пределы его на крыльях идей в пустое пространство чистого рассудка» [3, с. 57].

Коген, распознавая, как мы видели, в платоновском учении об идеях «критический мотив», не согласен с кантовской оценкой Платона. Для Когена кантовская трансцендентальная идея $u$ есть платоновская идея. Это важно понимать, потому что из этого отождествления проистекает вся платоническая специфика когеновского кантианства. Неокантианский Кант это неоплатонический Аристотель: и тот, и другой «углублены Платоном». 
Коген подмечает двусмысленность слова «идея», не оставленную Кантом без внимания. Поскольку «идея... никогда не может быть дана адекватно в конкретной действительности», то есть так, как это требуется чистым спекулятивным применением разума, то о ней, как о не вполне удачном понятии, можно было бы сказать: «это только идея». С другой стороны, имея в виду практическое применение разума, о ней нельзя так пренебрежительно говорить. Но даже для теоретического, спекулятивного разума идеи не излишни и не ничтожны, говорит Кант, так как «они незаметно служат рассудку каноном его широкого и согласного с собой применения» [3, c. 305-306]. В этом выражении «nur eine Idee», замечает Коген, таится ирония, имеющая обратный эффект, ведь его можно понять и так: одна только идея, и ничего кроме нее. И тогда в сравнении с так понятой идеей следовало бы сказать о предмете, «соответствующим образом данном в опыте понятию», что он - «только объект». Напротив, «иир - есть идея» [4, S. 74].

Такое обращение перспективы имеет своим следствием решающую для понимания когеновского кантианства перемену в соотношении формы и материи. Если нет ничего кроме идеи - пусть даже, в конще конщов, это идея практическая, - то она и определяющее, и определяемое. Как определяющее она - форма, как определяемое она - материя. Сама эта оппозиция «материя - форма» оказывается психологически и метафизически обусловленной, но ей нельзя придавать абсолютного значения: различие между материей и формой не логическое, но трансцендентальное 6 . Поэтому кантовские выражения «форма созерцания» (для пространства и времени) и «форма мышления» (для категорий) Коген расценивает как «пережиток метафизической дедукции» [4, S. 26]. Поэтому у Когена снимается кантовское противопоставление пространства-времени и категорий, и под общим именем «категорий» они возводятся к основоположениям - к тем функциям суждения, какие они в них выполняют. Поэтому Когеном, в конце концов, - поскольку «априорные, конститутивные условия опыта индуцируют (führen auf) не менее априорные регулятивные ограничения всякого опытного знания», то есть поскольку это требуется трансцендентальным a priori, - «категории расширяются до идей, а основоположения делаются систематическими единствами в максимах» [4, S. 152]. Коген делает это решительнее Канта, который, с одной стороны, понимал трансцендентальные идеи как расширенные категории («разум... превращает категорию в трансцендентальную идею, чтобы придать абсолютную полноту эмпирическому синтезу путем продолжения его до безусловного» [3, с. 356]), а с другой - предостерегал против трансцендентального употребления категорий, «выходящего за пределы всех чувственных предметов» [3, с. 255]. Хотя возможно, что у Канта одно не противоречит другому, ибо расширение (Erweiterung) не то же самое, что употребление (Anwendung), Коген тем не менее смещает центр тяжести в истолковании «формы», будь то пространство, время или какая-либо другая категория, на трансцендентальное употребление, «которое должно, к примеру, сделать понятной возможность геометрии» [4, S. 26]. Таким образом, обрисованное здесь методическое продвижение к условиям опыта есть не что иное, как радикализация того кантовского открытия, что «можно... посредством чувств созерцать a priori» [6, с. 194сн.], которое Коген воспринимает как побуждение к критическому исследованию самого Канта.

Это речение Канта, признающее здравую сущность чувственного восприятия, ставит перед Когеном проблему выбора: либо чувственность, либо разум. «Ибо a priori, - поясняет Коген, - означает закон, общий им обоим, а не свидетельство о рождении только для одного из них» [4, S. 2]. И тогда одно из двух: либо закон чувственности в этом созерцании становится законом разума, либо, наоборот, закон разума становится законом чувственности -

\footnotetext{
${ }^{6}$ Трансцендентальное различение, в отличие от логического, есть различение однородного и не ведет к противопоставлению.
} 
либо сенсуализм, либо интеллектуализм. Коген решительнее Канта выбирает интеллектуализм, без «снисхождения к чувственному восприятию и чувственности». Вместе с тем интеллектуализм Когена, не страдающий миопией кантовской «чувственности», не выходит за пределы возможного опыта, а всегда остается в связи с ним. Интеллектуализм Когена резче, нежели кантовский, есть эмпирический реализм ${ }^{7}$. У Канта границы возможного опыта определяются чувственностью, у Когена - не чувственностью, но самим разумом. Там, где у Канта граница между феноменальным и ноуменальным, «ее же не прейдеши», у Когена предельный переход: «Трансцендентальный метод стремится не только к полноте; он стремится научить устанавливать границы опыта. То есть он показывает, как категории переходят в идеи, явления в ноумены, основоположения в максимы» [4, S. 153].

Коррекция Когеном кантовской интеллектуальной оптики обращает метафизически обусловленную видимость в ви́дение: явления переходят в ноумены. Эта коррекция, прежде всего, есть исправление кантовского воззрения на природу и предмет математики и чистого естествознания.

Сумма этого воззрения, если иметь в виду критический период творчества Канта и не говорить здесь о позднем Канте, такова. В основе математики, как ее понимает Кант-критик, лежит чистое созерцание, формы которого - пространство и время. Применяется же математика «единственно к предметам чувств», к явлениям. Таким образом, математика, хотя она и чиста по своей природе, ограничена в своем применении чувственностью.

Предмет чистого естествознания - природа как коррелят возможного опыта. А именно: в материальном смысле природа есть совокупность всех предметов опыта, в формальном же смысле - совокупность всеобщих и необходимых их законов, то есть закономерная связь явлений, поскольку она познается a priori. Природа, рассматриваемая формально, есть не только предмет возможного опыта и выражающего этот опыт чистого естествознания, но и условие их, так что «субъективные законы, единственно делающие возможным опытное познание вещей, применимы и к этим вещам как предметам возможного опыта» [6, с. 72], то есть значимы объективно. Таким образом, чистое естествознание имеет своим предметом свою собственную природу; эта возникающая у Канта тема тождества субъекта и объекта, как общая тенденция трансцендентального метода и чистого естествознания, имеет важное значение для совместной работы философии и науки в направлении оснований объективной реальности, на чем настаивал Коген.

В чем же Коген не согласен с Кантом? Во-первых, он не принимает отождествления предметов возможного опыта с предметами чувств, с тем, что Кант называл явлениями. У Канта это так, поскольку сам возможный опыт есть «продукт рассудка из материалов чувственности» [6, с. 101]. Поэтому, как мы знаем, чувственность у Канта есть фактор, ограничивающий компетенцию математики и чистого естествознания: они не вправе применяться к вещам самим по себе. У Когена это не так: «так называемая» материя есть порочное дитя амфиболии рефлективных понятий, есть, так сказать, темная сторона формы, есть то, что Кант называл «вещью в явлении». Поэтому так называемая чувственность, как коррелят так называемой материи, на самом деле соотнесена с формой, с вещью в так называемом явлении и, стало быть, как и материя, она лишь привходящий момент идеи. Как материя однородна с формой, так и чувственность однородна с разумом. Только при таком воззрении на материю и чувственность можно понять, как это «чувствам так же надлежало бы созерцать a priori»Sinne auch a priori anschauen sollten.

\footnotetext{
${ }^{7}$ Примечательно, что об эмпирическом реализме - как о воззрении, согласном и даже совпадающем с трансцендентальным идеализмом - Кант говорит только в первом издании «Критики чистого разума».
} 
Стоит привести здесь два отрывка, чтобы дать слову самого Когена высказать это.

«Когда трансцендентальный метод научает распознавать в вещах, совокупность которых мы мыслим как материальный мир, явления, то есть постигать неизбежную и само собой разумеющуюся связь, которая устанавливается между объектом и созерцающе-мыслящим субъектом, тогда вновь дает себя знать амфиболия рефлективных понятий, и то, что с трансцендентальной точки зрения является первым, форма, затемняется (wird zurückgedrängt) первым [принципом] догматического реализма - материей» [4, S. 36].

«...Мы настолько непоправимо захвачены чувственностью, что всякий раз можем только снаружи, но никогда не в анализе мышления представлять себе так же [как материю] и формыл. ...В отношении законосообразного познания, мыслимого как проблема, и происходит это различение [между материей и формой]. Это «законосообразное» есть форма. То же, что посредством математических операций, соответствующих анализам, не может быть редуцировано [к форме], мы называем материей, пока мы не отыщем другого средства, чтобы в другой редакции проблемы разрешить то, что есть здесь еще проблематичного и подлежащего определению в своей законности. Таким образом обнаруживается, что необходимость, законосообразность познания и есть то, применительно к чему и в отношении к чему делается это различение» [4, S. 166].

Итак, для Когена, не страдающего миопией кантовской «чувственности», предмет возможного опыта, явление, не чувственный предмет. А что же? Вещь сама по себе. Вещи сами по себе суть явления, и в этом нет никакой видимости [4, S. 20]. Коген, в отличие от Канта, использует слово «явление» (Erscheinung) в точном значении греческого слова palvó являющееся; то, что является. Но что́ является? Вещь. Позже и Гуссерль в своей феноменологии будет использовать это слово в том же исконном его значении.

А если так, то вещь сама по себе познаваема? Да, познаваема. Вещи сами по себе означают у Когена не что иное, как основоположения, законы, и познаются постольку, поскольку познаются законы: «Совокупность законов, отнесенная к совокупности явлений, есть совокупность вещей самих по себе, познаваемых в природе явлений» [4, S. 29].

Соответственно, во-вторых, Коген не согласен с кантовской концепцией математики и чистого естествознания. Если пространство и время, понятые как формы созерцания, и категории, понятые как формы мышления, - «пережитки» метафизической дедукции, то с единственно правильной, трансцендентальной, точки зрения не они лежат в основе математики и чистого естествознания. Напротив, математика и чистое естествознание «сами собой» залегают в нашем духе, поскольку осуществляемое ими a priori есть форма его [4, S. 26]. Пространство, время, субстанция, причинность и другие категории суть условия возможного опыта и как таковые укоренены в духе, а стало быть, и в человеческом мышлении, будучи для нас непознаваемыми «последними формальными элементами» его. Математика и чистое естествознание укореняются Когеном глубже, чем Кантом: в конце концов, в идее мира, два аспекта которой - математическое понятие мира и динамическое трансцендентное понятие природы. Поэтому не из чистых форм созерцания и не из чистых форм мышления, связанных в основоположениях, объясняется возможность математики и чистого естествознания. Напротив, возможность самих чистых созерцаний и синтетических основоположений покоится на математике и чистом естествознании как на априорных формах самого духа: «Tеоретическое a priori означает некий закон учения об опыте. Но законы учения об опыте основываются, как бы не покантовски это ни звучало, на законах опыта. Если бы не существовало математических положений, то чистое созерцание не стало бы таким a priori. Не отыскалось бы и законов для так называемой природы, так что не было бы и никаких синтетических основоположений, которые ответственны за (stiften) единство опыта в тех законах» [4, S. 121]. 
Исправляя кантовское воззрение на природу математики и чистого естествознания, Коген проверяет справедливость своих выводов сопоставлением их - во втором издании «Кантовской теории опыта» (1885) - с достижениями современной ему науки. В частности, это хорошо видно на примере обсуждения Когеном вопроса о трехмерности пространства. Сама трехмерность его есть факт, обусловленный характером нашей чувственности, и в этом смысле психологический факт. Можно сказать почти наверное, что Коген не остался бы равнодушным к высказанной Т. Калуцей в 1919 году идее многомерия физического пространства, если бы ему хватило срока жизни, чтобы узнать о ней. (Чтобы придать наглядность этой идее, заметим: вытянутый волос представляется нам одномерным объектом, хотя для микроскопической фауны на его поверхности, если бы здесь было место сознанию, это скорее объект двух измерений.) Метафизическое рассмотрение пространства, отвлекающееся от содержания чувственного восприятия, дает нам представление лишь о форме чувственности: пространство есть чистое созерцание, и как таковое оно есть «представление одной лишь возможности сосуществования» [3, с. 328]. Но даже такое определение пространства не является необходимым для формулировки геометрических аксиом. В общей римановой геометрии, которую, очевидно, имеет в виду Коген, «сосуществуют» объекты с логически противоречивыми свойствами: например, треугольники, сумма углов которых как больше двух прямых углов, так и меньше двух прямых. Можно ли говорить о сосуществовании в одном пространстве, определение которого было бы предпослано этой геометрии в качестве необходимого ее условия, объектов с логически противоречивыми свойствами? - Только в том единственном случае, когда это «пространство» есть не что иное, как чистая форма самой геометрии, определяющая ее возможность и совершенно абстрагированная от чувственности. Таково кантовское трансцендентальное рассмотрение пространства, приспособленное Когеном к своему философскому интересу.

Задача установления условий, при которых наука возможна как имеющая силу a priori, может быть сформулирована и как задача реконструкции наличного опыта науки, насколько он значим a priori, в соответствии с его возможностью. Именно так понимает Коген задачу трансцендентального метода и вообще всей трансцендентальной философии в период работы над второй версией «Кантовской теории опыта» [7, S. 493]. Поскольку с устранением мнимой (признававшейся Кантом) зависимости математики и чистого естествознания от чувственности их компетенция распространяется на весь возможный опыт, также не ограниченный сферой чувственности, математика по праву может стать инструментом трансцендентальной философии. Трансцендентальный метод должен решить, как ожидает Коген, эту проблему: «соединение спекулятивных элементов с математикой и доступным наблюдению ощущением» $[7, \mathrm{~S} .72]^{8}$.

На эту возможность соединения спекулятивных элементов метода с математикой указывает и то отмеченное выше открытие Канта, что чистое естествознание, концептуальное ядро математического естествознания, есть учение о своей собственной природе, то есть об условиях опыта. Но такой рефлективной природой обладает и сам трансцендентальный метод: он тоже есть учение об условиях опыта. Поэтому как часть проблемы, обозначенной Когеном, представляется насущной для современной науки задача: произвести анализ универсальной концептуально-методической структуры фундаментальной физики с целью выявления в ней коррелятов ключевых элементов трансцендентального метода.

Эта задача - только начало пути, но путь этот неизбежен для научного сообщества, для тех «двойственных натур», в которых содействуют друг другу философская спекуляция и научная строгость.

\footnotetext{
${ }^{8}$ См. приложение.
} 
Представленный ниже перевод главы «Трансцендентальный метод» из Введения ко второму изданию «Кантовской теории опыта» был выполнен в органической связи с общим интересом, облеченным только что в форму задачи. Публикация этого перевода была отложена на годы после выхода в свет полного перевода на русский язык В.Н. Беловым третьего издания «Кантовской теории опыта» [8], которое в значительной мере повторяет второе издание. Переводческий труд Белова должен быть оценен по достоинству: переводить Когена - дело не из легких, отчего, быть может, он почти и не переведен на другие языки. Однако упомянутый общий интерес, отнюдь не «когеноведческий», побуждает нас представить теперь этот опыт перевода Когена, пусть и значительно уступающий по масштабу, явленному Беловым, но бывший для нас самих важной вехой, важным герменевтическим опытом. Перевод главы, имевшей для Когена программное значение, был и для нас элементом обязательной программы, поскольку идея трансцендентального метода привлекает наше внимание с давних пор. Помимо того, что существование разных переводов одних и тех же источников - вещь возможная и допустимая, чему немало примеров, публикуемый теперь перевод необходим как центральная часть, так сказать, «триптиха» текстов, объединенных под одним именем: «Герман Коген: идея трансцендентального метода».

\section{Список литературы}

1. Ein ungedrucktes Werk von Kant aus seinen letzten Lebensjahren // Altpreussische Monatsschrift 19-21 / Als Manuskript herausgegeben von R. Reicke. - 1882-1884.

2. Кант И. Opus postumum / пер. с нем. С.А. Чернова // Кант И. Из рукописного наследия (материалы к «Критике чистого разума», Opus postumum) / отв. ред. В.А. Жучков. - М.: Прогресс-Традиция, 2000. - С. 321-588.

3. Кант И. Критика чистого разума / пер. с нем. Н.О. Лосского с вариантами пер. на рус. и евр. языки / сост. В.А. Жучков. - М.: Наука, 1999. - 655 с.

4. Cohen H. Kants Begründung der Ethik. - Berlin: Dümmler, 1877. - 336 S.

5. Cohen H. Platons Ideenlehre und die Mathematik. - Marburg: Elwertsche, 1878. - 34 S.

6. Кант И. Пролегомены ко всякой будущей метафизике, могущей возникнуть в смысле науки / пер. с нем. В.С. Соловьева. - М.: Прогресс-VIA, 1993. - 240 с.

7. Cohen H. Kants Theorie der Erfahrung. - 2. Aufl. - Berlin: Dümmler, 1885. - $640 \mathrm{~S}$.

8. Коген Г. Теория опыта Канта / пер. с нем. В.Н. Белова. - М.: Академический проект, 2012. $-618 \mathrm{c}$.

9. Юм Д. Трактат о человеческой природе / пер. с англ. С.И. Церетели // Юм Д. Сочинения в 2 т. Т. 1. - 2-е изд., дополн. и испр. - М.: Мысль, 1996. - С. 53-655.

10. Локк Дж. Опыт о человеческом разумении / пер. с англ. А.Н. Савина // Локк Дж. Сочинения в 3 т. Т. 1 / ред. И.С. Нарский, А.Л. Субботин. - М.: Мысль, 1985. - С. 77-582.

11. Юм Д. О бессмертии души / пер. с англ. С.М. Роговина // Юм Д. Сочинения в 2 т. Т. 2. - 2-е изд., дополн. и испр. - М.: Мысль, 1996. - С. 689-697.

\section{References}

1. Ein ungedrucktes Werk von Kant aus seinen letzten Lebensjahren. Altpreussische Monatsschrift 19-21. Als Manuskript herausgegeben von R. Reicke. 1882-1884.

2. Kant I. [Opus postumum]. Kant I. Iz rukopisnogo naslediya (materialy $k$ «Kritike chistogo razuma», Opus postumum). Moscow, Progress-Tradiciya, 2000, pp. 321-588.

3. Kant I. Kritika chistogo razuma [Critique of pure reason]. Moscow, Nauka, 1999, 655 p.

4. Cohen H. Kants Begründung der Ethik. Berlin, Dümmler, 1877, $336 \mathrm{~S}$.

5. Cohen H. Platons Ideenlehre und die Mathematik. Marburg, Elwertsche, 1878, $34 \mathrm{~S}$. 
6. Kant I. Prolegomeny ko vsiakoi budushchei metafizike mogushchei vozniknut v smysle nauki [Prolegomena to any future metaphysics that can arise in the sense of science]. Moscow, Progress-VIA, 1993, $240 \mathrm{p}$.

7. Cohen H. Kants Theorie der Erfahrung. 2. Aufl. Berlin, Dümmler, 1885, $640 \mathrm{~S}$.

8. Cohen H. Teoriia opyta Kanta [Kant's theory of experience]. Moscow, Akademicheskii proekt, 2012, 618 p.

9. Hume D. Traktat o chelovecheskoi prirode [Treatise on human nature]. Vol. 1. 2nd ed. Moscow, Mysl', 1996, pp. 53-655.

10. Locke J. Opyt o chelovecheskom razumenii [An essay concerning human understanding]. Vol. 1. Moscow, Mysl', 1985, pp. $77-582$.

11. Hume D. O bessmertii dushi [On the immortality of the soul]. Vol. 2. 2nd ed. Moscow, Mysl', 1996, pp. 689-697.

\section{Приложение}

\section{ТРАНСЦЕНДЕНТАЛЬНЫЙ МЕТОД 1}

\section{Герман Коген}

Итак, исследование и характеристика познавательной ценности ньютоновского естествознания, а также основания достоверности его - вот, прежде всего, задача Канта, которую он сформулировал в условиях угрозы опытуㄹ․ В ответ на эту угрозу, разрабатывая так обозначенную задачу, Кант прибегает к сенсуалистскому оружию - как для того, чтобы этим же оружием защититься от вольностей (Übergriffe) сенсуализма, так и для того, чтобы, признав здравую сущность чувственного восприятия, усовершенствовать интеллектуализм. Конечно, неоспоримое преимущество на стороне последнего уже постольку, поскольку интеллектуализм не сводит подлинное основание познания к случайности представлений, но усваивает ему достоинство корня [человеческой] мысли - того, что, так сказать, ею наследуется; и это убеждение разделяется всеми творцами-рационалистами, несмотря на какие-то различия в деталях. Но чтобы сделать это убеждение действенным и плодотворным, мало приверженности самому интеллекту (Berufung auf den intellectus ipse) или снисхождения к чувственному восприятию и чувственности. Только особого рода работа над проблемами математического естествознания вместе с изучением его выдающихся авторов - только это и могло привести к постижению его оснований и предпосылок. Нельзя сказать, чтобы в самой Германии не было человека, способного соединить философскую спекуляцию с широко распространяющимися научными изысканиями: во все периоды своего творчества Кант заинтересованно следил за работами Леонарда Эйлера. Хотя и менее универсальной в этом смысле личностью, но весьма достойной в обоих отношениях был в Германии и Ламберт, поддерживавший теснейшую связь с Кантом. И все же более важной и решающей - с самого начала и постоянно - была для Канта связь с Ньютоном. Трансцендентальный метод возник в результате размышлений над «Математическими началами натуральной философии».

Уже термины, которыми пользуется Ньютон, обнаруживают свое происхождение из философских понятий. В трактате Ньютона называются и получают свое толкование пространство, время, движение, масса, причина, сила, инерция; в этих понятиях намечается фундамент физики. На предпосылки такого рода уже внешним образом указывают определения, равно как законы движения и regulae philosophandi, и так же явным образом Ньютон постоянно акценти-

\footnotetext{
1 (с) Тютюнников А.А. (пер. с нем.), 2018.

Перевод на русский язык публикуется в авторской редакции. S. $66-79$.

Перевод с немецкого языка выполнен по изданию: H. Cohen. Kants Theorie der Erfahrung, 2. Aufl. - Berlin: Dümmler, 1885. -

${ }^{2}$ Коген имеет в виду угрозу, которую представлял собой юмовский скептицизм в отношении познавательной ценности опыта.
} 
рует ту мысль, что он исследует явления, законы которых формулирует; гипотез же, которые должны давать основание этим законам, он не признает. Между тем сами явления зиждутся на этих понятиях, предпосланных Ньютоном как определениям, так и трем законам. Стало быть, общий фундамент как явлений, так и их законов залегает в этих основных понятиях. И что́ теперь они: гипотезы, которых физика должна избегать, или предпосылки, выгодно отличающиеся от явленных Коутсом ${ }^{3}$ скрытых свойств и гипотез «картезианцев»? Если можно, предъявив какой-нибудь факт, уладить и покончить с Юмовой «памятью», то этим фактом могло бы быть то, что законы и причины движения, устанавливаемые Ньютоном, имеют более глубокую основу, чем если бы они сводились к ассоциациям привычного опыта ${ }^{4}$.

Таким образом, для того чтобы найти основания науки, Канту пришлось осмыслить сам факт науки и то, как ее излагают. Но должны ли мы думать, что ему следовало бы изучать у ее творцов то именно, что́ в их открытиях послужило им побудительным или даже движущим мотивом? Разве за основание научного открытия должны приниматься - в своем качестве знаков - раскачивающаяся люстра в Пизанском соборе или падающее с дерева яблоко в пресловутом английском саду, когда дело идет об истине, когда оно идет о подлинном основании, а не о поводе психологического свойства? Или следовало бы сосредоточиться на утверждениях самих исследователей, когда и поскольку в этих утверждениях сказывается уже не исследователь, но - философ? Как же Кант пришел к своему трансцендентальному методу, если, хотя ему и необходимо было опираться на факт науки и ее представление в научной литературе, он тем не менее мог и должен был оставаться независимым от того и другого в исследовании, характеристике и формулировке ее оснований?

По-видимому, вопрос содержит ответ в себе самом: ведь Ньютон, как систематик своей науки, ни больше ни меньше - философ. Понятия, из которых он исходит, суть философские понятия. И не только Ньютон, но и родоначальник «новой науки» Галилей еще более определенно, чем Ньютон, являл и признавал в своих исследованиях содействие спекулятивного элемента и философских предпосылок - при всей своей постоянной приверженности опыту и наблюдению. Поэтому можно было бы подумать, что Канту стоило лишь принять во внимание эти коренные понятия, чтобы в отношении них разработать и испытать свой метод. Собрав те самые понятия, что в период от Галилея до Ньютона отчасти дискутируются публично, отчасти скрыто признаются, апробировать их - вот что могло бы показаться скромной задачей философского метода.

Однако метод никоим образом не есть трансляция основных понятий из плоскости исторического их определения в сферу философского оправдания. Хотя само это определение должно начинаться историческим сознанием и побуждаться им, однако ему необходимы особые философские обсуждения еще до того, как может начаться это оправдание. И в этих подготовительных работах - трудность трансцендентального метода. Если бы понятия, на которых держится подлинное основание познания, были наличны в достоверном фактическом материале, то как следует не было бы видно, что́ еще оставалось бы делать философии со своей стороны. Если, например,

\footnotetext{
${ }^{3}$ Кембриджский математик Роджер Коутс в предисловии к подготовленному им второму изданию Ньютоновых «Математических начал» резко полемизирует против картезианской гипотезы вихрей, увлекающих небесные тела. Он показывает, что у материи вихрей не может быть никаких свойств, которыми она отличалась бы от пустоты.

${ }^{4}$ Ср.: «Не будь у нас памяти, мы совсем не имели бы представления о причинности, а следовательно, и о той цепи причин и действий, из которых состоит наше я, или наша личность. Но, однажды приобретя с помощью памяти представление о причинности, мы можем простереть цепь причин, а следовательно, и тождество своей личности за пределы своей памяти, можем охватить мыслью времена, обстоятельства и поступки, которые совсем забыли, но которые вообще считаем некогда существовавшими... Итак, с данной точки зрения память не столько производит, сколько открывает личное тождество, указывая нам отношение причины и действия между нашими различными восприятиями. Те же, кто утверждает, будто память целиком производит наше личное тождество, должны будут объяснить, почему мы можем распространять последнее и за пределы нашей памяти» [9, с. 307].
} 
законы падения имеют своей предпосылкой философское понятие инерции, то философский метод ограничивался бы в данном случае лишь тем, чтобы разъяснить это частное обстоятельство; в чем бы тогда заключалась его самостоятельная, сколько-нибудь самобытная работа? Но, с другой стороны, для философского исследования познавательных ценностей представляется невозможным, не впадая в детский лепет, эмансипироваться и от фактов научных изысканий. Ибо что такое Вселенная, как не ставшая явью вечная истина, врожденная идея, несомненное свидетельство духа, тогда как опытное исследование, ограниченное ближайшим (die nächste Prüfung), самонадеянно сделало это абсолютно незначащим? Может быть, философия должна довольствоваться лишь тем, чтобы прокламировать основы познания, изобличаемые сменяющимися эпохами в качестве сравнительно неизменных факторов? Против этого недальновидного мнения говорит уже тот факт, наводящий на серьезные размышления, что новых основных понятий открывается очень мало, что во всех наших выводах и методах мы оперируем главным образом и преимущественно теми же основными понятиями, что передали нам греки - наши наставники в науке. Следовательно, задача философии лежит, вероятно, все-таки глубже, нежели бы она заключалась в подобном сравнительном анализе того, что сообщено нам со столь давних пор.

Здесь возникает другая трудность, которую трансцендентальный метод должен преодолеть. Судя по всему, подлинные движущие основания познания нельзя найти и утвердить в тех основаниях, из которых исходит исследователь и которые он выделяет в качестве таковых ведь между исследователями существуют разногласия о виде и количестве их; но, думается, в глубинах самого духа, в корнях мышления должно быть открыто то, что могло бы иметь силу в качестве источника науки и ее гаранта. Но отсюда же проистекает и опасность для критического метода: раствориться в методе психологическом и, вместо того чтобы определять ценности познания, лишь описывать его предполагаемые истоки и развитие - отойти, так сказать, от Платона к Аристотелю.

И все-таки кажется неизбежным, чтобы философский метод, исследующий ценность познания и с этой целью исследующий те самые основные понятия, которыми оно обусловлено, если и не совпадал с психологическим анализом, то по крайней мере соприкасался и объединялся с ним. Ведь познания - не химические субстанции, а психические образования и процессы. Как поэтому было бы возможно при их исследовании обойтись без тех средств и способов, что дает для своих дистинкций психология? Когда Ньютон исходит, например, из «пространства», за какой вид понятия нам следует его принять? Здесь нам на ум тотчас же приходит традиционное различение: является ли это самое «пространство» понятием мышления или оно продукт чувственного восприятия? То же и «причина», требуемая Ньютоном, является она продуктом такого же рода или ее нужно квалифицировать как некое своеобразие того, что мы именуем «мышлением»? Если мы теперь обратимся к исходному для Ньютона понятию массы, то затруднение усиливается, так как в этом понятии, пожалуй, можно было бы усмотреть запутанность сразу обоих видов психической деятельности. Уже из этого краткого обсуждения видно, что критический метод, по всей вероятности, недееспособен без метода психологического. Создается поэтому впечатление, будто психологи-сенсуалисты - продолжатели Декарта и разрабатывают те же проблемы, что Декарт и Лейбниц. Но все-таки это совсем не те же самые проблемы; и по различию устремлений рационалистов и сенсуалистов можно отчетливо различить между тем и другим методом.

В самом деле, интерес психологии в отношении основных понятий познания совершенно иной, нежели интерес метода, который мы разыскиваем. Локк, если только он последователен, может не признавать существования последней структуры сознания, к которой он вви- 
ду дальнейшей ее неразложимости должен был бы отнестись как к своей задаче. Законный интерес психологии состоит в том, чтобы, не признавая никаких так называемых врожденных идей, показывать все идеи в той последовательности, в какой с самого начала они обнаруживаются. Как, посредством чего и благодаря какому соединению представлений мы приходим к понятию причинности - вот что есть и всегда остается интересом психологии, каким бы ни было решение о ценности этого понятия как основного понятия опыта. Точно так же никакой другой интерес не может помешать ее интересу в вопросе о том, каким образом - при посредстве и связывании каких чувственных восприятий - мы приходим к представлению о пространстве. Такого рода вопросы генезиса (Entwicklungsgeschichte) ставятся с полным правом и в отношении душевных образований. Таким образом, по-видимому, оба интереса идут рука об руку - независимо и равноправно; более того, казалось, что критический интерес даже обусловлен психологическим, поскольку познания суть психологические процессы.

Но дальнейшее рассуждение должно показать теперь, что психология не менее зависит от критического интереса. Ибо к каким элементам сводит она свой анализ? К ощущениям. Что, однако, подразумевается под ощущениями в качестве элементов сознания? Ведь не нервными же возбуждениями характеризуется сознание. Что соответствует в сознании элементарным движениям нервной системы? На эти вопросы даже и в наши дни даются различные ответы, в зависимости от того гипотетического начала, из которого, как полагают, нужно исходить при конструировании сознания. Однако английские сенсуалисты мало сомневались в этом пункте. Они понимали «сильные» ощущения как впечатления от вещей, а идеи как копии этих впечатлений. Но разве это психология? Не будет ли вернее сказать, что вещи и впечатления от них суть понятия, имеющие отношение к содержанию и ценности познания, а не к описанию познавательных процессов? Мы понимаем, стало быть, что мнимый психологический интерес скрывает под собой интерес критический - ситуация фатальным образом типичная.

Ибо уже Декарт указал на ту принципиальную ошибку, что идеи принимают за отражения вещей и потому исходят из вещей. И что характерно: хотя и не как методолог, но как психолог Декарт допускает тем не менее в ощущениях наличие материальных идей и впечатлений от вещей. Так в итоге бывает всегда, как если бы этот итог был фатально предрешен, когда ввязываются в психологию. Стало быть, во впечатлениях кроется какой-то критический предрассудок (Vorurteil). А потому психология впечатлений не только зависит от этого другого способа философского исследования, но и упреждает его. В этом - непоправимая ненаучность ее исходного пункта.

А потому те рационалисты, что способствовали формированию науки и привнесли в нее важнейшие инструментальные понятия, взяли за исходный пункт математику, видя, при помощи каких основных понятий конституируется математическое познание природы. Они не могли только прийти к ясности в характеристике этих основных понятий и не могли установить простую связь мышления с ощущением, истин разума (vérités de raison) с истинами факта (vérités de fait). Сенсуалисты потому и одержали верх, что они по крайней мере умели говорить ясно и, в общем-то, без обиняков. От нового метода следует прежде всего ожидать, что он сможет прийти к правильному определению этой связи. Ибо это проблема, которая коренится уже в слове «опыт» (Erfahrung): соединение спекулятивных элементов с математикой и доступным наблюдению ощущением.

Но не так-то легко теперь философу даже просто-напросто увидеть эти спекулятивные элементы в представлениях Галилея или Ньютона, так как оба исследователя столь же мало преуспели в критическом их рассмотрении, сколь и Декарт с Лейбницем. Стало быть, он все- 
таки, по-видимому, вынужден волей-неволей заниматься психологией; ведь дело в структурах сознания, в фактах его. Что́ в сознании процесса познания является ощущением, а что́ - мышлением, этого нельзя решить по крайней мере без психологических дистинкций. Так что новый метод, по-видимому, опять-таки вынужден взаимодействовать с психологией, если и вовсе не переходить в нее. Пусть только он предохранит себя от некритического допущения вещей, производящих впечатления.

Однако этой предосторожностью дело не ограничивается, ибо порок исходного пункта психологии распространяется и на дальнейшее. Когда мы хотим установить основания, из которых исходит Ньютон, этот изначальный порок ее оказывается постоянной помехой. Мы хотим знать, какое значение имеет для геометрии и оснащаемого ею естествознания пространство; и Юм дает нам психологический ответ, что пространство есть идея, которая возникает из повторяющихся восприятий цветных точек ${ }^{5}$. Стало быть, пространство, о значении которого для познания предметов мы спрашиваем, есть копия впечатлений, что должны происходить от точек, а значит, от вещей. Стало быть, вещи тут даны, и в принципе нет нужды исследовать те незамысловатые способы, которыми они могут быть обусловлены. Они, вне всякого сомнения, наличны. Что бы ни было - не это подлежит сомнению скептика. Так ненаучность установки, исходящей из вещей, пускает корни в анализ познания, и далее - в основания познания. Новый метод, несмотря на то, что он не может обойтись без языка психологии (так как речь идет о продуктах психики), должен поэтому даже и в пределах психологического анализа, насколько он им пользуется, преследовать свой собственный интерес, опровергать присущий этому анализу критический предрассудок и таким образом давать самой психологии научную опору.

Так, при анализе тех фактов сознания, что конституируют познание (и поскольку они конституируют его), должно все же сохраняться внутреннее различие в направленности методов. Ввиду этого различия исследование на предварительном этапе трансцендентального метода Кант, позаимствовав термин, называет «метафизическим». И это метафизическое предварение есть в то же самое время исправление психологического предрассудка. Психологу-аналитику необходимо осознать, что существуют границы его анализа, признание которых [во-первых] есть признак критической зрелости и установления которых [во-вторых] требует критический интерес.

Мы хотим два последних момента рассмотреть отдельно и прежде всего обдумать, в какой мере признание объективных границ психологического анализа является симптомом освобождения от психологического предрассудка.

Так вот [во-nервblx], весь свет постепенно пришел к осознанию того, что мы не понимаем, не постигаем непосредственно и само по себе, что́ есть сознание. Это весьма ясно сознавал уже Локк, и не менее ясно это осознание выражено в проблеме окказионализма ${ }^{6}$. Но если мы осознае́м, что не можем понять сам факт обладания нами сознанием, то тем самым не признае́м ли мы фактически, что должны существовать элементы сознания, которые не поддаются психологическому анализу? Ибо что означает наше непонимание того, что́ есть сознание, как не то, что мы не понимаем, что́ есть сознание пространства, или сознание субстанции, или сознание причинности?

Правда, существуют разногласия о том именно, являются ли пространство, субстанция и причинность такими последними элементами сознания. Допустим, что в этих частных случаях могут быть разногласия; но все-таки не может быть разногласий о том, что вообще

\footnotetext{
5 «...Идея протяжения не что иное, как копия... цветных точек и способа их появления» [9, с. 93].

6 Проблема взаимодействия души и тела. Это взаимодействие не может быть постигнуто как причинно-следственное отношение ввиду непостижимости последнего основания вещей, то есть Бога, и, стало быть, все движения души и тела являются, с нашей точки зрения, лишь движениями «по поводу», но не «по причине».
} 
должны существовать какие-то последние элементы сознания. Ибо всеобщее выражение сознания должно все-таки мыслиться в каких-то определенностях. Поэтому вполне оправданна задача - разложить эти определенности сформированного сознания и реконструировать их из гипотетических элементов; так что уже сама эта задача прямо влечет за собой допущение гипотетических элементов, каковые, однако, непременно должны быть элементами сознания, а не чем-то вроде элементов нервных движений. Если бы мы могли допустить, чтобы сознание без остатка растворилось в последних, оно тем самым стало бы постижимым. Как только мы признае́м его само по себе непостижимым, мы ставим непреодолимые границы психологическому анализу; если, конечно, не полагать это сознание совершенно закрытым от нас в невнятной его абстрактности, не задумываясь о том, что всякое ens должно быть quale ${ }^{7}$ Если непостижимо сознание вообще, то должны быть непостижимыми и какие-то его модификации. Таким образом, допущение «нерастворимых» элементов сознания есть признак критической зрелости.

Но [во-вторых] есть необходимость утверждать такие элементы, продиктованная критическим интересом. С этой точки зрения Кант воспринял термин «а priori», который у Лейбница и особенно у его последователей стал ключевым словом. Хотя «a priori» у Канта как мы увидим это более конкретно, но пока лишь судя по включенности его в состав трансцендентального метода, - должно по своей мотивации, а потому и по своему содержанию означать нечто другое, тем не менее оно настолько связано с более ранним своим значением, что и у Канта, и у Лейбница этим «a priori» констатируется некий элемент познавательного процесса, остающийся скрытым от психологического анализа. И тем, что исследование на предварительном этапе трансцендентального метода устанавливает такое a priori, оно в силу этой направленности и в силу этого своего результата отличается от психологического исследования. Такое исследование фактов сознания в познавательном процессе, которое устанавливает недоступные для психологического анализа - точнее сказать, признаваемые в качестве априорных - элементы сознания, Кант называет «метафизическим рассмотрением» (metaphysische Erörterung) $)^{8}$. И оно есть необходимое предварительное условие трансцендентального.

Теперь можно поставить вопрос о том, почему трансцендентальный метод предпосылает себе метод метафизический и почему выделение таких элементов требуется критическим интересом. Разве не могли бы мы определить познавательную ценность науки единственно уже тем, что указали бы на основания процесса познания как таковые, не заботясь о том, являются ли они элементами человеческого сознания? Зачем нам ввязываться в дискуссию психологов, зачем сознательно, по примеру самих исследователей, не положить в основу то, что является с необходимостью? Ведь a priori в таком выводе из оснований признано исследователями; зачем искать a priori в каком-то другом, менее относительном смысле? Если я хочу знать, на каких основаниях и предпосылках покоится математическое естествознание, то, спрашивается, какая польза и даже необходимость в том, что я осознаю недоступность этих оснований для психологического анализа и неподатливость их для какой-либо психологической обработки в качестве первоэлементов сознания в его чистоте - и, следовательно, в том (применяясь к интересующему нас вопросу), что об-

\footnotetext{
${ }^{7}$ Другими словами: утверждать постижимость сознания - значит отрицать его существование. В психологическом анализе сознания может быть постигнуто лишь то, каково (quale) оно, да и то отчасти. Но сознание как еns, как «сущее, поскольку оно суще, вкупе с тем, что присуще ему самому по себе» (Аристотель. Метафизика. 1003 а 21-22), недоступно для психологического анализа. Однако в том, «что присуще ему самому по себе», в своих «определенностях», или, говоря иначе, в своей всеобщей категориально-логической структуре, оно все же остается мыслимым, вне пределов психологии, - хотя и не познаваемым в последних, «нерастворимых» своих элементах, - выступая одновременно как предмет науки и как объект трансцендентального метода.

${ }^{8}$ Cм. [3, c. 78].
} 
ладание ими оказывается для нас столь же загадочным, как и само сознание, относительно которого Локк и Юм признают, что оно почти так же непостижимо, как и материя?

Этот вопрос приводит нас к своеобразию философского метода, в отличие от исторического ознакомления с теми предпосылками, что выявляются или подмечаются в трудах исследователей; но вместе с тем он вновь приводит нас к «осложнению» критического метода психологией, от которой первый отличается утверждением a priori.

Чем же продиктована необходимость такого отличения, если не говорить о той пользе, какую может извлечь из него психология для собственного своего прояснения? Чем продиктована, ради цели и выгоды самого критического метода, необходимость признания таких априорных элементов? Вполне может показаться, будто трансцендентальный метод завершается в метафизическом, а не только предпосылает его себе. Кажется, что путем демонстрации наличия таких элементов философский метод должен был бы окончательно доказать свою независимость и самобытность. Видимость эта обманчива; но то, что трансцендентальное обоснование не может быть осуществлено и даже не может начаться без метафизической констатации, - должно быть ясно с самого начала.

А именно допустим, что не существует таких особенностей сознания, в которых в чистом виде сказывается характер познавательного процесса; тогда следствием этого было бы то, что процесс так называемого «познания» осуществлялся бы нами в произвольных или, в крайнем случае, психологически обусловленных комбинациях. Нельзя было бы сказать, что я конституирую вещь как совокупность (Inbegriff) свойств, если бы основную черту того, что мы именуем духом, являл собой образ действий, в котором преимущественно было бы задействовано то, что называется «мышлением»; а следовало бы сказать, что игра наших фантазий, обуздываемая разве только привычкой, вспенивает эти пузыри разума. Таким образом и характер самой науки был бы фантомом этих традиционных привычек. Оппозиция априоризму имеет своим следствием скептицизм. Вера в действенную значимость науки основывается поэтому на гипотезе существования особенных элементов и свойств, характерных для познающего, наделенного духом сознания, в которых сама наука обретает свое основание и свою гарантию. Наука состояла бы из приблизительного, если бы в комбинациях восприятий и произвольности этих комбинаций заключалась причина того, что восприятия соединяются в науку, если бы она не была укоренена в основаниях сознания, которые мы можем обнаружить в качестве модусов и определенностей его, недоступных анализу.

Ибо откуда взялись бы те понятия, из которых исходит Ньютон? Порождаются ли они в результате каких-то привычных ему комбинаций или происходят решительно в силу известной его приверженности античной традиции, которая в свое время также выделила эти понятия? Не так ли и Галилей? Ведь и он не смог эмансипироваться от этих понятий, между тем как в остальном он так яро противостоял своему Аристотелю. И если Юм прав в том, что эти понятия суть достояние привычки, то не зиждется ли тогда ньютоновская наука на произвольных, лишь на привычке основанных предположениях? Напротив, не должны ли эти понятия, если науке суждено идти вперед, быть действенными в качестве элементов и оснований

${ }^{9}$ Локк пишет о первой материи в своем «Опыте о человеческом разумении»: «...Это первичное и будто бы очевидное качество тела окажется, если его исследовать, столь же непостижимым, как все относящееся к нашему уму, а плотную протяженную субстанцию так же трудно представить себе, как и субстанцию мыслящую и нематериальную, какие бы возражения против этого ни выдвигались» [10, с. 361].

То же и Юм. Например, в эссе «О бессмертии души»: «Метафизические доводы предполагают, что душа нематериальна и невозможно, чтобы мышление принадлежало материальной субстанции. Но истинная метафизика учит нас, что представление о субстанции полностью смутно и несовершенно и что мы не имеем другой идеи субстанции, кроме идеи агрегата отдельных свойств, присущих неведомому нечто. Поэтому материя и дух в сущности своей равно неизвестны, и мы не можем определить, какие свойства присущи той или другому» [11, с. 689-690]. 
познающего сознания, что лежат по ту сторону всякой подконтрольной ему привычки и тем самым образуют фундамент и правооснование науки?

Таким образом мы видим, что доверие к действенной значимости науки связано с гипотезой существования оснований сознания, отправляясь от которых и развивая которые наука ведет свою историю. Между тем эта гипотеза должна оградить себя от двух опасностей. Во-первых, при характеристике и более точном определении элементов подобного рода должна методически исключаться всякая пристрастность. Во-вторых, нельзя усматривать решение этой задачи на пути структурирования этих элементов как элементов индивидуального человеческого сознания. Преодолением второй опасности преодолевается и первая, и притом она снимается методически.

Какие заблуждения могут соединяться с гипотезой существования априорных понятий, достаточно обнаруживает история философии и наук. Что здесь присутствуют основные понятия с этим необходимо согласиться; какие же именно - все возрастающее понимание этого станет следствием прогрессирующей культуры духа. А потому метафизическое рассмотрение по своим результатам имеет временную и относительную ценность; лишь задача его и направленность безусловно необходимы и имеют гарантированную значимость. Достаточно ли, к примеру, нам будет причинности или необходимо допустить еще некий целевой элемент сознания, - этого нельзя найти при метафизическом рассмотрении. Также нельзя найти этим способом и то, как должно быть сформулировано основное понятие причинности: то ли в качестве закона основания, то ли так, что благодаря ему определяются реальные изменения как таковые. Остается ли в куске воска в качестве «пра-вещи» (Ur-Ding) нечто протяженное (что-то более абстрактное или же более плотное), что непосредственно обусловливало бы в сознании, со своей стороны, элемент субстанции, - в этом метафизическое a priori само по себе не дает нам удостовериться.

В этом удостоверяет нас трансцендентальный метод, принцип и норма которого заключены в простой мысли: элементы познающего сознания суть те и такие элементы сознания, что необходимы и достаточны для обоснования и утверждения факта науки. Определенность априорных элементов сообразуется, стало быть, с этим их отношением к фактам научного познания, подлежащим посредством их обоснованию, и с компетенцией их в этом смысле. Считается, например, что для науки необходимо и конститутивно значимо понятие системы, так что необходимо будет отыскать элемент сознания, который в своей всеобщности соответствует этой отличительной черте науки. Таким образом метафизическое рассмотрение переходит в трансцендентальное, но последнее ни в коем случае не сводится к первому. Элементы сознания должны быть действенными в качестве оснований науки, а предпосылки науки должны проявляться в качестве основных черт познающего сознания. A priori метафизическое должно стать трансцендентальным a priori. Так Лейбниц, очищенный от Юма, достигает полного развития в Канте, опирающемся на Ньютона.

Как представляется, это не было лишено целесообразности - предварительно наметить здесь тот метод, в соответствии с которым совершены кантовские открытия. Если бы еще и теперь нельзя было не спросить, как, по какому счастливому стечению обстоятельств может такое быть, что упомянутые двойные ${ }^{10}$ анализы так слаженны, то это был бы вопрос к истории науки, словно бы к волшебной сказке ${ }^{11}$. Но поскольку наука не волшебная сказка, постольку и удается найти в ее основных понятиях, засвидетельствованных в научной литературе, вовсе не чудесное согласие с наиболее всеобщими истинами логики - истинами, которые с давних пор

\footnotetext{
${ }_{11}^{10}$ То есть метафизические, переходящие в трансцендентальные.

11 Психоаналитическая параллель к этому месту (хотя и позднейшая): волшебная сказка у Карла Юнга есть конкретизация архетипа коллективного бессознательного. Когеновские априорные элементы познающего сознания залегают все же глубже, чем юнговские архетипы человеческого духа.
} 
были извлечены из хаоса мышления спекулятивным разумом. Нет, не из хаоса мышления - но из результатов и проблем научной мысли тех времен абстрагировала свою всеобщность логика. Эта научная мысль ведет от греков, прежде всего от Архимеда, минуя пропасть Средних веков, к ренессансу науки. Следовательно, нет ничего чудесного в том, что у Галилея и Ньютона работают и приносят плоды те же основные идеи, что подвигали уже греков и произрастали из математики и механики.

И наконец, разве не является человеческая мысль на самом деле тем, что тут и там - как в сущности логики, так и в материнском лоне науки - действует как один и тот же, и притом единственный, фермент? Только не следует определять эту мысль в индивидуальном образе действий, но - по преимущественным выражениям ее: в разуме и науке. Этому определению сопутствует как удивление по поводу неожиданного соответствия между логикой и наукой, так и, наоборот, - скептицизм. Кто грезит о неопределенной, неясной необходимости, тот не найдет ее в науке. Если бы он был влеком к науке тем энтузиазмом, каким были исполнены сами исследователи и натуры «двойственные», [соединившие спекуляцию и науку], то он направил бы добродетель усердия на то, чтобы оправдать веру в науку и обосновать фактический состав ее в ее необходимых и достаточных условиях.

Трансцендентальный метод разоблачает скептицизм, который вообще борется против априорных элементов, будучи в основе своей недалеким догматизмом. В качестве ясного и зрелого убеждения о том единственном начале, из которого может исходить философское исследование и в виду которого оно может достигнуть полезного результата, трансцендентальный метод оправдывает веру в науку, как оправдывает и допущение неразрывно связанных с нею, изъятых из игры ассоциаций и абсолютно необходимых оснований. Скептицизм есть естественное следствие сенсуализма. Но интеллектуализм, вместе с метафизическим a priori, укореняется в мысли, которая привела к науке и которая зиждет ее, а в трансцендентальном методе он делает науку постижимой - тем способом, что сообразуется с присущей ей необходимостью.

Получено: 23.03.2018

Принято к печати: 14.05.2018 